\title{
Pigmented Lesions of the Retinal Pigment Epithelium and Familial Adenomatous Polyposis.
}

\author{
P. J. POLKINGHORNE, ${ }^{*}$ S. RITCHIE, $\dagger$ K. NEALE, $\dagger$ G. SCHOEPPNER, ${ }^{*}$ \\ J. P. S. THOMSON $\dagger$ and B. S. JAY.* \\ London
}

\begin{abstract}
Summary
Bilateral pigmented fundus lesions were found in 65 out of 72 patients with familial adenomatous polyposis, an additional five patients having unilateral lesions. With a family history of familial adenomatous polyposis, the occurrence of multiple bilateral fundus lesions indicates the presence of the abnormal gene, as does the occurrence of oval pigmented lesions with surrounding pale haloes. The absence of pigmented fundus lesions does not exclude the abnormal genotype, while the presence of occasional pigmented spots can be found in an appreciable percentage of the population. Ocular examination would, however, appear to be valuable in screening those at risk, with a positive yield in most carriers of the gene for familial adenomatous polyposis.
\end{abstract}

In 1980 an association between congenital hypertrophy of the retinal pigment epithelium (CHRPE) and Gardner's syndrome was described, ${ }^{1}$ and this association was later confirmed by other workers. ${ }^{2-6}$ Gardner's syndrome is characterised by intestinal adenomatous polyposis and various soft tissue and bony tumours, transmitted as an autosomal dominant trait. More recently it has become apparent that CHRPE occurs in patients with familial adenomatous polyposis without the other extracolonic manifestations described in Gardner's syndrome..$^{7-12}$ The term Gardner's syndrome has tended to be replaced by familial adenomatous polyposis.

Familial adenomatous polyposis is a syndrome characterised by the occurrence of multiple adenomas in the gastrointestinal tract. These polyps, which usually exceed 500 and may be as numerous as 10,000 in the large bowel alone, have considerable potential for malignant transformation. ${ }^{13}$ The polyps are often evident from early adult life but may not become manifest until the fourth decade of life. For individuals at risk of developing the disorder, screening by sigmoidoscopy is recommended annually from the age of 14 years. Affected individuals are usually managed by removing the greater part or all the large intestine as a prophylactic measure to prevent the development of large intestinal carcinoma. ${ }^{14}$

Although the association of CHRPE and familial adenomatous polyposis is now well established, some of the features of the pigmented fundus lesions remain unclear and warrant further study. It has not been established whether these lesions change with age, nor is it clear if they are found in individuals at risk of developing polyposis. Furthermore considerable variation in the prevalence of retinal lesions in affected individuals has been

From: *Department of Clinical Ophthalmology, Moorfields Eye Hospital, London and †The Polyposis Registry, St Mark's Hospital for Diseases of the Rectum and Colon, London.

Correspondence to: Professor Barrie Jay, Moorfields Eye Hospital, City Road, London EC1V 2PD 


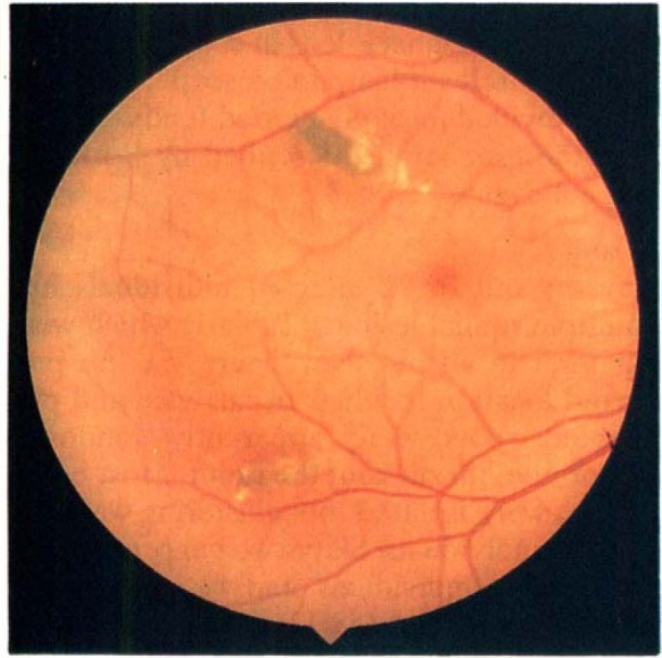

Fig. 1 a

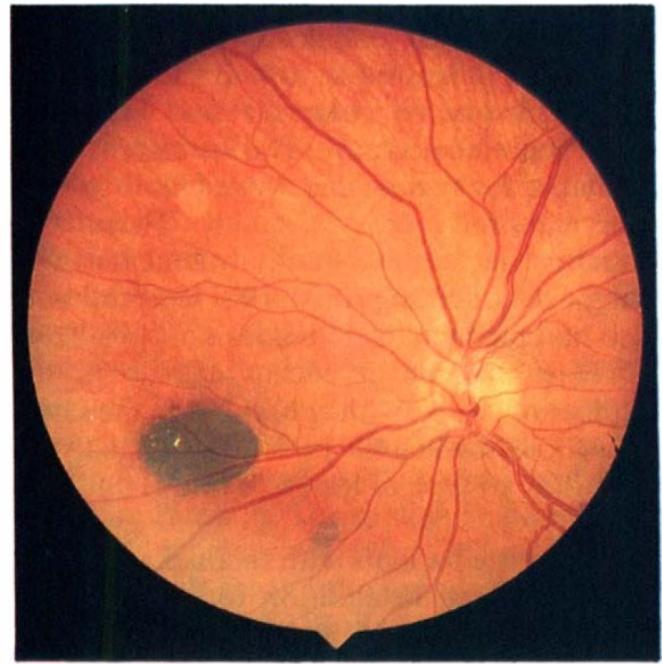

Fig. $1 c$

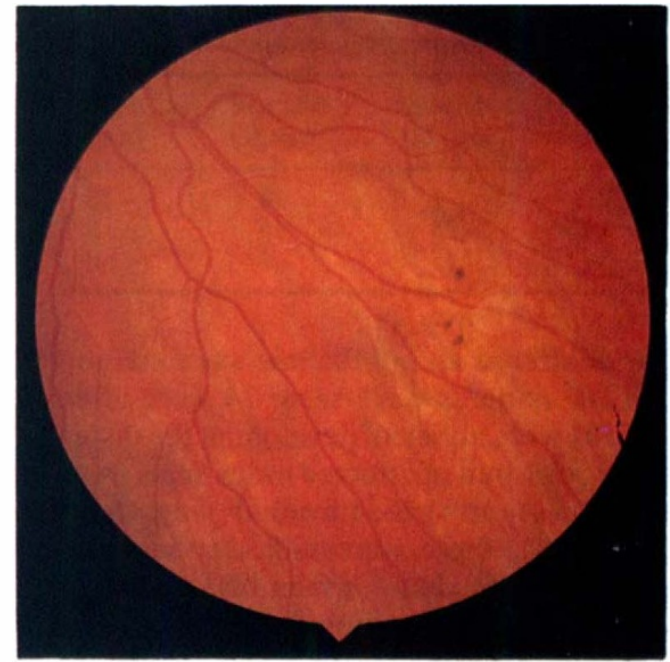

Fig it

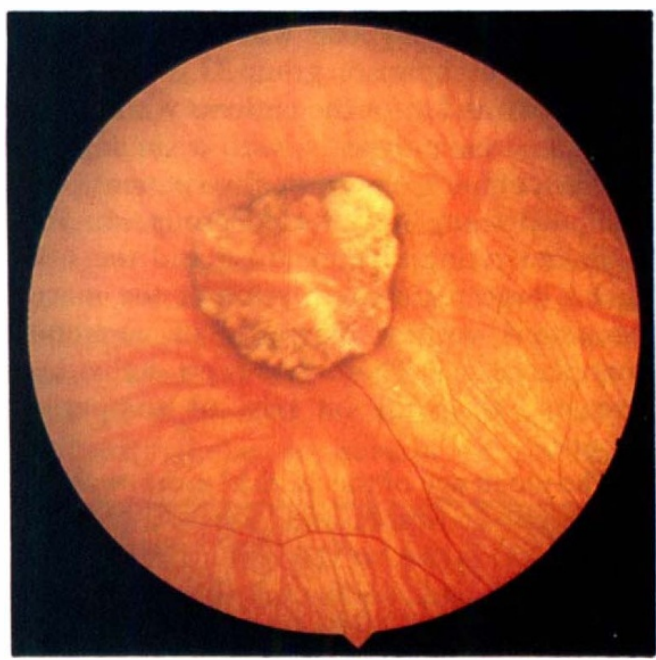

Fig 1d

Fig. 1. The 4 types of fundus lesion as described by Berk et al. ${ }^{10}$ :

i) a-oval pigmented lesion with surrounding pale halo;

ii) $b$-small round pigmented dot;

iii) c-large pigmented spot; and

iv) d-large atrophic lesion with or without a pigmented halo.

reported. ${ }^{1,4,12}$ This variation has not been satisfactorily explained and, while it may reflect differences in techniques of examination or diagnostic criteria, other mechanisms may be at work. We have attempted to address these questions by studying a large well-documented population of patients with familial adenomatous polyposis.

\section{Patients and Methods}

All patients attending the Polyposis Clinic at St Mark's Hospital over a six month period 
Table I Absolute number of pigmented retinal lesions in patients with familial adenomatous polyposis and in the 'at risk' and comparison groups

\begin{tabular}{cccc}
\hline $\begin{array}{c}\text { No. of } \\
\text { Lesions }\end{array}$ & $\begin{array}{c}\text { Affected } \\
(n=72)\end{array}$ & $\begin{array}{c}\text { 'At risk' } \\
(n=31)\end{array}$ & $\begin{array}{c}\text { Comparison } \\
(n=26)\end{array}$ \\
\hline 0 & 2 & 14 & 18 \\
$1-5$ & 25 & 15 & 8 \\
$>5$ & 45 & 2 & 0 \\
\hline
\end{tabular}

were offered an ophthalmic examination. In all 105 patients were seen: 74 were affected and 31 were at risk of developing the disorder, being children of affected individuals. A comparison group of 26 individuals were similarly evaluated; these were either spouses of an affected individual, or members of non polyposis families attending the clinic with other conditions. The polyposis status of all 131 individuals was unknown to the examiner at the time of ophthalmoscopy.

The mean age of the patients with familial adenomatous polyposis was 38.25 years and that of the comparison group 37.25 years. The sex ratio was $1: 1$ for the patients with familial adenomatous polyposis, with a similar ratio for the comparison group. Two patients were excluded from the affected group: one had $\mathrm{X}$-linked retinitis pigmentosa and the other had a large pigmented lesion at the macula consistent with a diagnosis of congenital toxoplasmosis. There were no individuals excluded from the 'at risk' or comparison groups.

The mean age of the 'at risk' group was 19.6 years, with 16 women and 15 men. Four of the individuals in the 'at risk' group had at least one rectal macroadenoma but none had multiple adenomas. These four 'at risk' individuals were each less than 17 years of age.

Examination of the ocular fundi was per- formed through a maximally dilated pupil using both indirect ophthalmoscopy and a +90 dioptre aspheric lens in conjunction with a Haag-Streit slit lamp microscope.

We divided focal pigmented fundus lesions into the four groups described by Berk and her colleagues ${ }^{10}$ (Fig. 1).

\section{Results}

Seventy out of 72 affected individuals had multiple retinal lesions (Table I) which were bilateral in all but five. There was no preferred location for their occurrence and pigmented spots were apparently randomly distributed throughout the fundi. Most of the lesions were isolated, but clustering was seen in a few individuals. Sixty-two per cent (45/72) of affected individuals had type A lesions while 80 per cent $(58 / 72)$ had two or more types of lesion. The 72 patients in this group had, between them, 603 retinal lesions. Two patients with familial adenomatous polyposis had no lesions in their fundi. These two individuals had their diagnosis of familial adenomatous polyposis reviewed. Both had a family history of polyposis and both had undergone a colectomy. The specimens were available for review and were found to contain hundreds of adenomas. These two patients had other family members with polyposis attending St Mark's Hospital who also had pigmented retinal lesions.

There was no significant change in the number of lesions with age, either in the series as a whole or when the patients were analysed according to type of lesion (Table II and Fig. 2).

One of the patients with familial adenomatous polyposis, in addition to bilateral pigmented lesions, had albinotic spots of the retinal pigment epithelium simulating 'polar bear tracks' ${ }^{15}$ (Fig. 3).

Table II Total number of lesions and number of lesions by type, broken down by decade, in patients with familial adenomatous polyposis

\begin{tabular}{ccccrrr}
\hline Age & $\begin{array}{c}\text { Number } \\
\text { subjects }\end{array}$ & $\begin{array}{c}\text { Total No. } \\
\text { lesions }\end{array}$ & $A$ & \multicolumn{2}{c}{ No. of lesions by type } \\
\hline $16-25$ & 18 & 180 & 42 & 111 & 20 & 7 \\
$26-35$ & 17 & 104 & 18 & 69 & 9 & 8 \\
$36-45$ & 16 & 130 & 31 & 81 & 13 & 5 \\
$46-55$ & 11 & 98 & 17 & 70 & 5 & 6 \\
$56-65$ & 8 & 74 & 5 & 44 & 13 & 12 \\
over 65 & 2 & 17 & 0 & 16 & 0 & 1 \\
\hline
\end{tabular}




\section{NUMBER OF LESIONS}

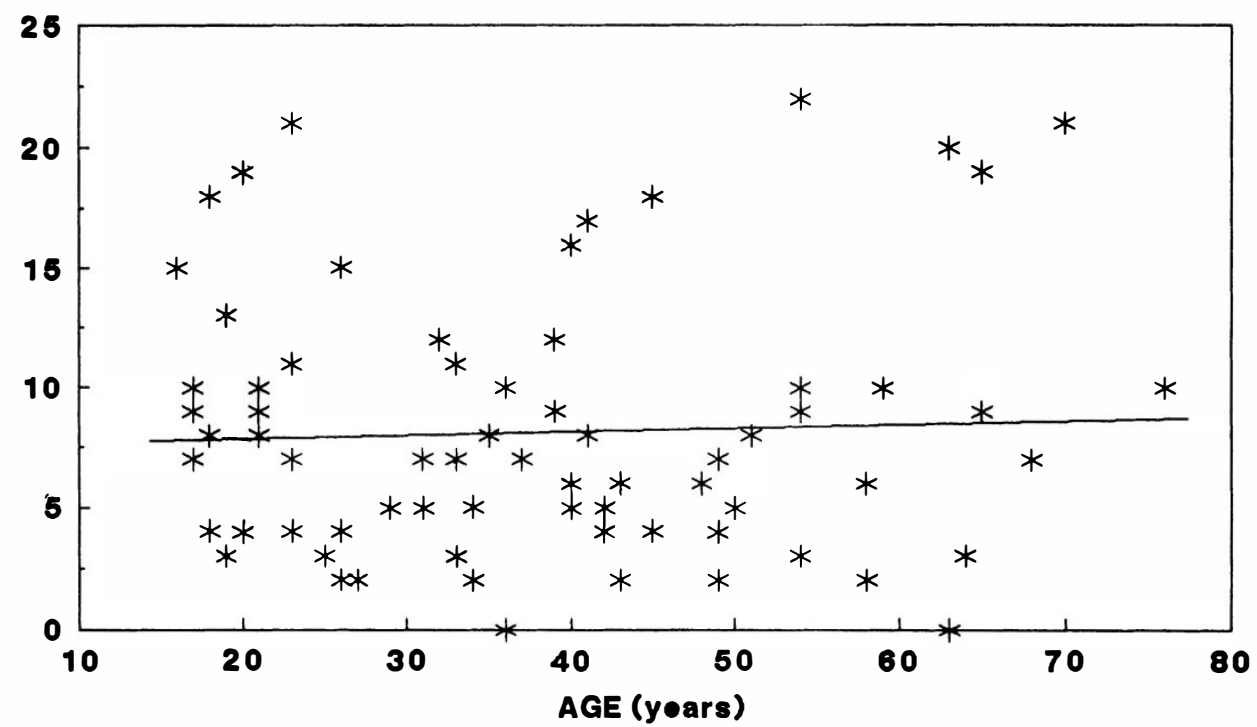

Fig. 2. Affected patients: number of pigmented fundus lesions plotted against age.

Individuals in the 'at risk' group were members of 20 kindreds, and each had an affected parent. In the 20 kindreds there were 61 offspring of whom we were able to contact and examine 45 . Fourteen of these were already affected and are analysed with the affected group. We found in the 31 'at risk' individuals, eight with bilateral pigmented lesions and nine with unilateral involvement. Two 'at risk' individuals had more than five lesions (Table I) and none had more than eight; only two had a type A lesion (see Fig. 1). Six had more than one type of lesion. The small pigmented spots of $50 \mu \mathrm{m}$ in diameter (type B lesion) comprised 60 per cent of the lesions found in the 'at risk' group. The 31 members of this group had, between them, 50 retinal lesions.

Of the 26 individuals in the comparison group, 18 had no lesions and eight had between one and five lesions in their fundi. Of these latter eight individuals, only two had more than one type of lesion, four of the eight had bilateral lesions, but none of the eight had a type A lesion. The number of lesions present in the affected group differed significantly from that both in the 'at risk' group $(\mathrm{p}<0.001)$ and in the comparison group $(\mathrm{p}<0.001)$ (Table I). The difference between the 'at risk' and comparison groups was less significant $(0.2<\mathrm{p}<0.1)$.

\section{Discussion}

This study confirms the observation that multiple pigmented retinal lesions of the retinal pigment epithelium are reliable markers for patients with familial adenomatous polyposis.

In our study, $97 \%$ of affected individuals had pigmented lesions which were predominantly bilateral and multiple. This prevalence of pigmented lesions in the affected group is similar to several in the liter-

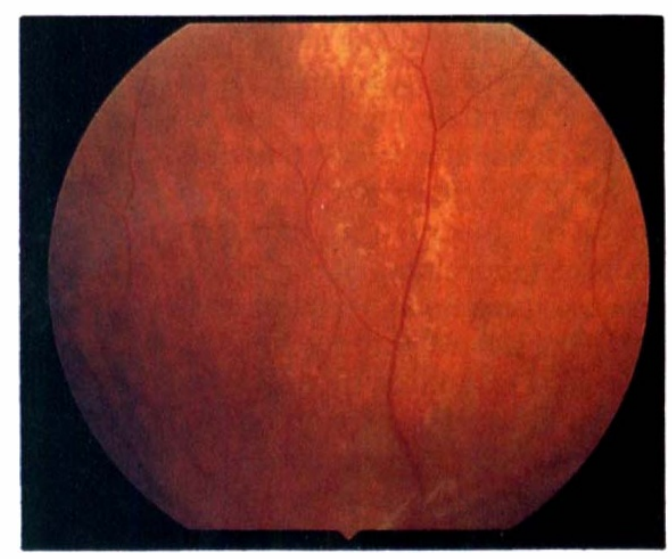

Fig. 3. Grouped albinotic spots of the retinal pigment epithelium ('polar bear tracks') in patient with familial adenomatous polyposis. 
ature, ${ }^{4,10,12}$ but higher than some other reports. Two thirds of the affected individuals had type A lesions which were not found in the comparison group. This suggests that, in the presence of a family history of familial adenomatous polyposis, this lesion, which appears to be unique to familial adenomatous polyposis, ${ }^{10}$ indicates the presence of the abnormal genotype. This oval pigmented (type A) lesion has been recorded in patients with familial adenomatous polyposis by other authors, but its prevalence has not been quoted.

Type B lesions were the most frequent lesion in both the affected and comparison groups. However in the latter the number of lesions was small and they were more likely to be the sole type of hyperpigmentation of the retinal pigment epithelium. Type $\mathrm{C}$ and $\mathrm{D}$ lesions were occasionally seen in the comparison group. In our comparison group eight out of 26 had between one and five pigmented lesions. This compares with Traboulsi and his co-workers ${ }^{4}$ who found small unilateral lesions in 14 and small bilateral lesions in two out of 42 controls, and Chapman and her coworkers $^{12}$ who found one or two lesions in 15 out of 35 of their control group. It would therefore appear that about $30-40 \%$ of normal individuals have a few pigmented lesions in their fundi.

The patient with grouped white spots of the pigment epithelium (Fig. 3) has an appearance not previously described in association with familial adenomatous polyposis. Although this could be a fortuitous finding, it is more probably of significance, in view of the variety of other pigment epithelial defects seen in familial adenomatous polyposis.

Variable expressivity is commonly seen in conditions inherited as autosomal dominant traits and the finding of two individuals in our series without any retinal lesion is not surprising. This should not be interpreted as representing a variant of the underlying disorder especially as pigmented lesions were found in other members of these families. For a similar reason the variation in number and type of lesion was not unexpected.

The 72 affected individuals had between them 603 retinal lesions, an average of over eight lesions per individual, while the 31 members of the 'at risk' group had between them only 50 lesions. Assuming that half the 'at risk' group will be carrying the mutant gene for familial adenomatous polyposis, there is still a paucity of lesions in this group. This difference in the absolute number of retinal lesions between the 'at risk' and affected individuals in our study may reflect a chance finding, or may indicate either variable expressivity or that the lesions are not always congenital.

Eight 'at risk' individuals had bilateral pigmented lesions but only two had a large enough number (more than five lesions) to suggest they had inherited the abnormal gene. Another two individuals had a type A lesion and a further three individuals had two types of lesion. Thus a total of seven 'at risk' individuals might be assumed to have inherited the abnormal gene.

The differences documented between the number and variety of pigmented lesions in the affected and 'at risk' groups have not been described before. Only one other report has surveyed a large number of individuals at risk of developing familial adenomatous polyposis. ${ }^{4}$ They found in 16 kindreds with familial adenomatous polyposis (with extra-colonic manifestations) approximately half of the 'at risk' individuals had bilateral lesions, which were indistinguishable from those of the affected group. Blair and Trempe ${ }^{1}$ included two 'at risk' patients in their series, one of whom had multiple oval to round hyperpigmented lesions.

The congenital nature of these pigmented retinal lesions is suggested by the terminology and supported by the clinical similarity with unilateral, solitary, pigmented lesions of 1-2 disc diameters in size. However, congenital hypertrophy of the retinal pigment epithelium has not been shown to be inherited. Conversely the pigmented lesions seen in association with familial adenomatous polyposis are familial, multiple and of different shapes and dimensions. The presence of pigmented lesions in neonates and young children, at risk of developing familial adenomatous polyposis, does not rule out that some of these lesions also may be acquired. Furthermore, Baker and his colleagues ${ }^{11}$ have noted that the other phenotypic manifestations of familial adenomatous polyposis are hyperplastic and 
they cautioned against accepting that the lesions seen in familial adenomatous polyposis were hypertrophic. However, hyperplasia has been described in at least one case of CHRPE. ${ }^{16}$ Gass $^{15}$ has argued that the evidence for all focal pigmented anomalies of the pigment epithelium of the retina being congenital was not proven and that a number of processes may produce a similar clinical lesion.

We did not find a difference in the number of lesions with age, and this is in favour of these lesions being congenital, although none of our patients was under 16 years of age. We believe, however, that while these lesions may be congenital, certain differences exist between the pigmented lesions of 'classical' CHRPE and those associated with familial adenomatous polyposis. The use of the term 'CHRPE' in association with familial adenomatous polyposis is, therefore, probably inappropriate.

We believe, in common with others, ${ }^{4,12}$ that the presence of multiple bilateral pigmented fundus lesions in a person at risk of developing familial adenomatous polyposis suggests inheritance of the abnormal gene, while the presence of one or more type A lesion is even stronger evidence for this. While the absence of pigmented lesions does not exclude the diagnosis, ocular examination would appear to be a valuable and simple means of detecting carriers of the gene for familial adenomatous polyposis. The combination of sigmoidoscopy and examination for CHRPE will sharpen the clinician's ability to diagnose familial adenomatous polyposis. Genetic testing will, when freely available, further assist in the diagnosis.

We wish to thank the Consultant Surgeons at St Mark's Hospital for agreeing to our studying patients under their care.

\section{References}

${ }^{1}$ Blair NP and Trempe CL. Hypertrophy of the retinal pigment epithelium associated with Gardner's syndrome. Am J Ophthalmol 1980, 90: 661-7.
${ }^{2}$ Lewis RA, Crowder WE, Eirman LA, Nussbamm RL, Ferrell RE. The Gardner syndrome: significance of ocular features. Ophthalmology 1984, 91: 916-25.

${ }^{3}$ Buettner H. Kongenitale Hypertrophie des Pigmentepithels der Netzhaut und Gardner-Syndrom. Fortschr Ophthalmol 1986, 83: 597-9.

${ }^{4}$ Traboulsi EI, Krush AJ, Gardner EJ, Booker SV, Offerhaus GJA, Yarldey JH, Hamilton SR, Luk GD, Giardiello FM, Welsh SB, Hughes JP, Maumenee IH. Prevalence and importance of pigmented ocular fundus lesions in Gardner's syndrome. $N$ Eng J Med 1987, 316: 661-7.

${ }^{5}$ Stein EA and Brady KD. Ophthalmologic and electro-oculographic findings in Gardner's syndrome. Am J Ophthalmol 1988; 106: 326-31.

${ }^{6}$ Lyons LA, Lewis RA, Strong LC, Zuckerbrod S, Ferrell RE. A genetic study of Gardner syndrome and congenital hypertrophy of the retinal pigment epithelium. Am J Hum Genet 1988, 42: 290-6.

${ }^{7}$ Lynch HT, Priluck I, Fitzsimmins ML. Congenital hypertrophy of retinal pigment epithelium in nonGardner's polyposis kindreds. Lancet 1987, ii: 333.

${ }^{8}$ Li FP, Thurber WA, Seddon J, Holmes GE. Hepatoblastoma in families with polyposis coli. J Am Med Ass 1987, 257: 2475-7.

${ }^{9}$ Llopis MD and Menezo JL. Congenital hypertrophy of the retinal pigment epithelium and familial polyposis of the colon. Am J Ophthalmol 1987, 103: $235-6$.

${ }^{10}$ Berk T, Cohen Z, McLeod RS, Parker JA. Congenital hypertrophy of the retinal pigment epithelium as a marker for familial adenomatous polyposis. Dis Colon Rectum 1988, 31: 253-7.

${ }^{11}$ Baker RH, Heinemann M-H, Miller HH, DeCosse JJ. Hyperpigmented lesions of the retinal pigment epithelium in familial adenomatous polyposis. Am J Med Genet 1988, 31: 427-35.

${ }^{12}$ Chapman PD, Church W, Burn J, Gunn A. Congenital hypertrophy of the retinal pigment epithelium: a sign of familial adenomatous polyposis. $\mathrm{Br}$ Med J 1989, 298: 353-4.

${ }^{13}$ Bussey HJR. Familial Polyposis Coli. Family Studies, Histopathology, Differential Diagnosis, and Results of Treatment. Baltimore: John Hopkins University Press. 1975.

${ }^{14}$ Bussey HJR, Eyers AA, Ritchie SM, Thomson JPS. The rectum in adenomatous polyposis: the St Mark's policy. Br J Surg 1985, 72: 529-31.

${ }^{15}$ Gass JDM. Focal congenital anomalies of the retinal pigment epithelium. Eye 1989, 3: 1-18.

${ }^{16}$ Wirz K, Lee WR, Coaker T. Progressive changes in congenital hypertrophy of the retinal pigment epithelium. Graefes Arch Clin Exp Ophthalmol 1982, 219: 214-21. 